\title{
THE EFFECT OF BIOACTIVE CHITOSAN NANOPARTICLES ON MI- CRO-SHEAR BOND STRENGTH TO DENTIN (AN IN VITRO STUDY)
}

\author{
Wakwak MA* and Farghaly $\mathrm{AM}^{* *}$
}

\begin{abstract}
This study evaluated the effect of three different anti-bacterial cleansing agents on microshear bond strength to dentin with self etching bonding agent. Materials\&Methods; Flat dentin surface of 120 molars was prepared, samples was divided into four main equal groups (30 teeth each) according to the type of disinfectant pretreatment; group(D1) Chitosan nanoparticles (CNPs), group (D2) Cetylpyridinum chloride (CPC), group (D3) Pomegranate peel extracts (PPE) and group (D4) Control (no pretreatment). Selfetch adhesive system G-aenial bond and Kalore resin composite was applied. Microshear bond strength testing was done using universal testing machine. Result; the highest mean microshear bond strength $(27.139 \pm 2.72 \mathrm{MPa})$ was recorded for those dentin specimens treated with (CNPs)after 1day storage time while the lowest mean shear bond strength (15.33 $\pm 2.44 \mathrm{MPa})$ was recorded for those dentin specimens treated with (PPE) after 3 months storage time Conclusions; (CNPs) application before bonding with self-etch adhesive preserve bond strength over time.
\end{abstract}

\section{INTRODUCTION}

The longevity of resin composite restoration is directly related to the stability of the hybrid layer. However, the methacrylate polymers of adhesive systems may undergo chemical hydrolysis and enzymatic degradation by the metalloproteinases ${ }^{(1)}$. Inhibiting the action of metalloproteinases and preventing degradation of the hybrid layer requires the use of cavity pretreatments, adhesive systems resistant to the action of collagenolytic enzymes ${ }^{(2)}$. Chitosan (CNPs) is a non-toxic cationic biopolymer usually obtained by alkaline deacetylation from chitin $^{(3)}$. The covalent immobilization of chitosan on dentinal collagen has been proposed to induce the remineralization of the exposed and demineralized dentin structure because its functional phosphate groups might bind to calcium ions to form a favorable surface for crystal nucleation, resulting in the formation of a calcium phosphate layer ${ }^{(4)}$. Chitosan treatment improves the resistance of the dentinal surface to degradation by collagenase $\mathrm{e}^{(5)}$. Furthermore, chitosan presents with biocompatibility, chelating capacity and also antimicrobial effect ${ }^{(6-9)}$. Previous in vitro studies have demonstrated the significant antibiofilm efficacy of chitosan nanoparticles (CNPs) ${ }^{(7)}$. Chitosan has been used to promote the biomimetic reconstruction of enamel and inhibit biofilm formation on titanium implant surfaces ${ }^{(6,7)}$. The incorporation of chitosan in experimental adhesive systems improve the biological and mechanical properties of collagen construction and enhance antibacterial activity by means of ionic interactions between chitosan and the bacterial cells ${ }^{(8)}$. Inhibition of MMPs action and hence collagen degradation has been also attempted to improve the longevity of the resin-dentin interface and the MMP inhibitor has been used as a separate dentin preconditioning step ${ }^{(10)}$. The hyposis of this study was directed to study the effect of different anti-bacterial cleansing agents on microshear bond strength to dentin.

* Lecturer of operative dentistry, Faculty of Dental Medicine, Al-Azhar University (Cairo-Boys).

** Assistant professor of Endodontics, Faculty of Dental Medicine, Al-Azhar University, Cairo(Boys) 


\section{MATERIALS AND METHODS}

Chitosan nanoparticles(CNP) ${ }^{1}$ : 0.2 gram chitosan were dissolved in $50 \mathrm{ml}$ distilled water contains $0.5 \mathrm{ml}$ acetic acid. Then TPP solution contains $0.06 \mathrm{gm}$ was dropped into the chitosan beaker at room temperature. After that chitosan solution was magnetically stirred for $45 \mathrm{mins}$ to obtain chitosan nanoparticles. These chitosan nanoparticles could be stably stored in distilled water ${ }^{(11)}$.

Cetylpyridinum chloride(CPC $)^{2}$ : Cetylpyridinium chloride is a quaternary ammonium compound and is the active chemical antimicrobial activity is due to an interaction of basic cetylpyridin- ium ions with acidic molecules on bacteria, which subsequently inhibits bacterial metabolism by forming weak ionic compounds that interfere with bacterial respiration. CPC has been shown to be effective for poultry washes at concentrations of $0.5 \%$, giving reductions of up to $2.5^{(12)}$.

Pomegranate peel extracts(PPE $)^{3}$ : Pomegranate peel extracts (hydroalcoholic extract) from Punica granatum (pomegranate fruits) activity on dental plaque microorganisms rich in polyphenols have been demonstrated to exhibit a strong radical scavenging effect, and antibacterial activity against gram-positive and gram-negative bacteria.

\section{MATERIALS AND METHODS}

All the materials compositions are listed according to the manufacturer's profile.

TABLE (1) Adhesive bonding system and Composite resin:

\begin{tabular}{|l|l|l|l|l|}
\hline Material & Specification & Content & Manufacturer & Manuf. No. \\
\hline $\begin{array}{l}\text { Kalore } \\
\text { ShadeA3 }\end{array}$ & $\begin{array}{l}\text { Nano-hybrid } \\
\text { composite }\end{array}$ & $\begin{array}{l}\text { Urethane dimethacrylate (UDMA) 18\%, DX-511 } \\
\text { co-monomer, Fillers (Fluoroaluminosilicate glass), } \\
\text { Prepolymerized filler, Silicon dioxide, photo initiator, } \\
\text { Pigment }\end{array}$ & $\begin{array}{l}\text { GC, Tokyo Japan } \\
\text { (1010091) website } \\
\text { www.gc-dental.com }\end{array}$ & 386006 \\
\hline $\begin{array}{l}\text { G-aenial } \\
\text { (One step) }\end{array}$ & $\begin{array}{l}\text { Self etch } \\
\text { adhesive }\end{array}$ & $\begin{array}{l}\text { 4-Methacryloxyethyltrimllitate anhydride 5-10\%, acetone } \\
\text { 30-40\%, water 15-20\%, Dimethacrylat 15-20\%, phosphoric } \\
\text { acid ester monomer 15-20\%, silicon dioxide 1-5\%, } \\
\text { photoinitiator }\end{array}$ & $\begin{array}{l}\text { GC, Tokyo Japan } \\
\text { (12101121) Website } \\
\text { www.gc-dental.com }\end{array}$ & N123319 \\
\hline
\end{tabular}

Specimens preparation for microshear bond strength test;

A total of one hundred and twenty human permanent molars. Flat dentin surface were produce using carbide burs ${ }^{4}$ in high-speed handpiece with profuse water-coolant by creating a depth cut grooves of $2 \mathrm{~mm}$ at the occlusal surface. A graduated periodontal probe was used to confirm the depth.
These grooves were united together to create a flat tooth surface (the bur was replaced after 3 preparations).

The molars were randomly divided into four equal main groups of thirty specimens each according to the three tested disinfectant agents and a control group. In the first group, the dentin surface were subjected to Chitosan Nanoparticles (CNPs)

1. Pure Chitosan nanoparticles, Naqaa Foundation for Scientific Research \& Nanotechnology, Giza, Egypt.

2. Pure Cetylpyridinum chloride, B Fresh, Pharo Pharma, Egypt.

3. Pure Pomegranate Peel Extract, Aquamint, Roxeen Pharma, Egypt

4. - \#245SC carbide burs, Brasseler, Savannah, GA, USA. 
pretreatment, the second group were pretreated with Cetylpyridinum chloride (CPC) to dentin surface, the third group were receive Pomegranate peel extracts(PPE) pretreatment, and the fourth group did not receive disinfectant pretreatment (control group).

The bonding procedures was done by using G-aenial selfetch adhesive system according to the manufacturers' instructions which applied to the entire walls of the preparations with a micro-brush and lifted for 10 seconds, to allow evaporation of acetone solvent and deeply penetration of the adhesive followed by drying $5 \mathrm{sec}$ and light cured for $10 \mathrm{sec}$. After adhesive resin application and prior to curing on each specimen, hollow cylinders with an internal diameter approximately $1 \mathrm{~mm}$ and height of $2 \mathrm{~mm}$ were cut from plastic pediatric catheter microtube*. Four irises were mounted on each treated dentin surface and held on the surface to restrict the bonding area (2 iris for testing and the others as a supplemental for any error). $1 \mathrm{~mm}$ increment of resin composite was applied in the iris and condensed with pluger and light cured for 20 $\mathrm{sec}$ and another layer of $1 \mathrm{~mm}$ was applied and cured for $20 \mathrm{sec}$.

\section{Microshear bond strength testing;}

Each tooth embedded in acrylic mould with its own bonded resin composite microcylinders was secured with tightening screws to the lower fixed compartment of a universal testing machine (fig.1) with a load cell of $5 \mathrm{kN}$ and the data was recorded using computer software. A wire loop prepared from orthodontic stainless steel ligature wire was looped around the bonded resin composite microcylinder assembly as close as possible to the base of the resin composite microcylinder and aligned with the loading axis of the upper movable compartment of the testing machine. A micro-shearing load with tensile mode of force was applied via universal testing machine at a crosshead speed of $1 \mathrm{~mm} / \mathrm{min}$.

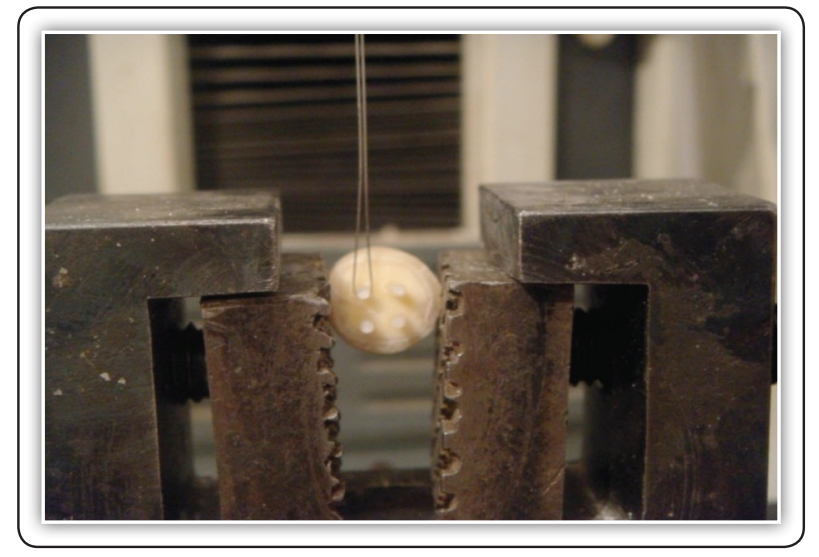

FIG (1) A wire loop around the bonded resin composite microcylinder loaded in testing machine.

The relatively slow crosshead speed was selected to produce a shearing force that resulted in debonding of the resin composite microcylinder along the dentin-adhesive interface. The load required for debonding was recorded in Newton.

\section{Scanning electron microscope examination:}

Finally, (random specimens) one tooth from each group that used for disinfectant treatment at the end of storage time (one day, one month and three months) were used for scanning electron microscope examination to evaluate failure mode distribution to study the effect of various treatments on the dentin surface topography.

\section{RESULTS}

From table (2) After 1 month, (CNPs) group showed the highest mean microshear bond strength. There was no statistically significant difference between (CPC), (PPE) and control groups which showed the statistically significantly lowest means microshear bond strength. While After 3 months, (CNPs) group showed the statistically significantly highest mean microshear bond strength. There was no statistically significant difference between (CPC), (PPE) and control groups which showed the statistically significantly lowest means microshear bond strength.

* Pediateric catheter: Ultramid Company, Brussels, Belghum. 
TABLE (2): Mean microshear, standard deviation (SD) values

\begin{tabular}{|c|c|c|c|c|c|c|c|c|c|}
\hline \multirow{2}{*}{$\begin{array}{l}\text { Group } \\
\text { Period }\end{array}$} & \multicolumn{2}{|c|}{ CNPs } & \multicolumn{2}{|c|}{ CPC } & \multicolumn{2}{|c|}{ PPE } & \multicolumn{2}{|c|}{ Control } & \multirow{2}{*}{$P$-value } \\
\hline & Mean & SD & Mean & SD & Mean & SD & Mean & SD & \\
\hline 1 day & $27.13^{\mathrm{a}}$ & 2.72 & $22.83^{b}$ & 3.87 & $22.18^{b}$ & 4.68 & $22.34^{b}$ & 4.14 & $0.046^{*}$ \\
\hline 1 month & $18.98^{\mathrm{a}}$ & 2.43 & $16.57^{b}$ & 2.47 & $15.46^{b}$ & 2.20 & $15.34^{b}$ & 2.50 & $0.018 *$ \\
\hline 3 months & $18.75^{\mathrm{a}}$ & 2.14 & $16.10^{b}$ & 3.12 & $15.33^{b}$ & 2.44 & $16.59^{b}$ & 3.15 & $0.042 *$ \\
\hline
\end{tabular}

*: Significant at $P \leq 0.05$, Means with different letters are statistically significantly different according to Tukey's test.

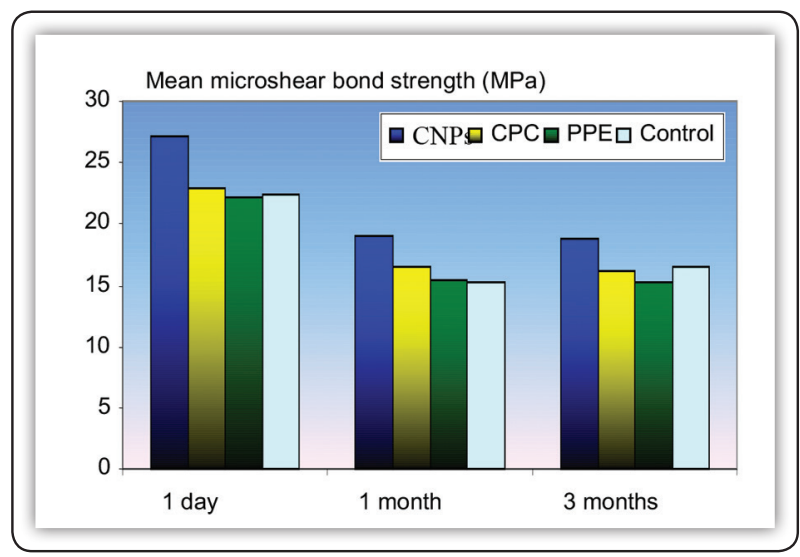

FIG (2) Mean microshear bond strength of the four groups.

\section{Scanning Electron Microscopy SEM observations of failure mode.}

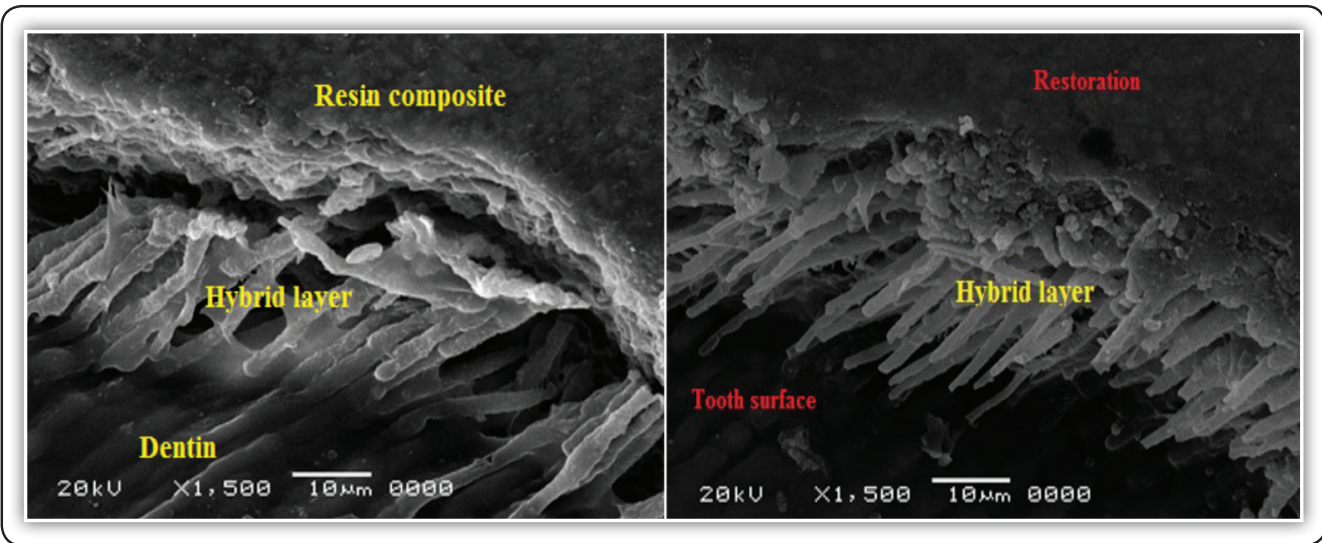

FIG (3) SEM photomicrograph (at 1500X) for CNPs disinfection; A) after one day of storage showing mixed failure (part of composite resin can be seen in the tubules) while, B) after one month storage showing adhesive failure showing the dentin exposed with some tags of resin remaining in the tubules. 


\section{DISCUSSION}

The results of this study suggest that optimum bond strengthening of dentin can be achieved throughout the immediate adhesive treatment with (CNPs). Initial results have proven that this significant increase in bond strength and the durability of resin dentin bond lasts for a prolonged time.

The use of three antimicrobial agents; Chitosan is a potent antioxidant with multiple free hydroxyl groups. These hydroxyl groups can form bridge-type hydrogen bonds within the side chains of hydroxyl, carboxyl, amino or amide groups of the collagen molecules $^{(14)}$. The formation of these hydrogen bonds is the reason of the stability of chitosan with dentin collagen ${ }^{(15)}$. Cetylpyridinium chloride as a mouthrinse (containing $0.05 \%$ ) was as effective in reducing viable bacteria in oral spatter ${ }^{(16)}$. Pomegranate peel extracts rich in polyphenols have been demonstrated to exhibit a strong radical scavenging effect, and antibacterial activity against gram-positive and gram-negative bacteria and direct removal of plaque from the teeth ${ }^{(17)}$.

SEM images of the dentin surface exposed to (CNPs) has been significantly influenced by the unique properties of the chitosan in promoting a formation of the hydroxyapatite crystals, as well as prevent demineralization of enamel and dentin ${ }^{(18)}$. The potential applications of chitosan strengthening the collagen matrix, increasing resin-dentine bond strength, inactivation of collagen-bound proteases and remineralization of root caries ${ }^{(19)}$.

In 2012, Elsaka ${ }^{(20)}$ reported a study evaluating the antimicrobial activity and the adhesive property of dental adhesive containing various incremental concentrations of chitosan. It was reported that these properties improved upon addition of chitosan. Upon addition of 0.12 and $0.25 \%(\mathrm{w} / \mathrm{w})$ chitosan, the micro tensile bond strength values were better compared to the control group, however there were no significant differences. Lobato et $\boldsymbol{a l}^{(21)}$, proposed that networks containing covalently crosslinked chitosan could be considered as smart hydrogels with dentinal collagen. The lowest bond strength value was found in (PPE), while CNPs presented the highest bond strength value. One of the explanations for this occurrence is the greater complexity of the adhesive bond to dentin ${ }^{(22)}$. Another probable explanation is related to demineralized dentin drying. The collapse of collagen fibrils and establishment of hydrogen bridges between them may occur, contracting and tensing the collagen network, and leading to the loss of the tridimensional spatial configuration. Thus, the permeability of this network is diminished, which hinders the infiltration of the adhesive monomers, leading to the formation of a thinner hybrid layer with deficient sealing of the dentinal tubules ${ }^{(23,24)}$.

The monomer/solvent combination in adhesive systems with their application performed in a larger number of steps must be capable of breaking the interpeptide hydrogen bridges, and thus re-expand the dentin matrix, recreating the interfibrillar spaces of the collapsed collagen network to allow infiltration of the hydrophobic monomer ${ }^{(25)}$.

The bond strength, measured by means of the microshear test, varied with the treatment of the exposed tooth surface. Inferior behavior was observed for Groups (CPC) and (PPE), in which the self-etching adhesive system was used, and which removes a micrometric layer of dental surface ${ }^{(26-28)}$. Shallower tags in dentinal tubule was verified with self etching process, not allowing better flow of the hydro-phobic monomer, without more deeper tag formation $^{(29)}$.

Conclusions; (CNPs) application before bonding with self-etch adhesive preserve bond strength over time. Using CNPs, CPC and PPE has no adverse effect on the bond strength. Storage in water for long periods has a highly significant adverse effect on the bond strength to all groups especially with surface treated with PPE and with no surface treatment. 


\section{REFERENCES}

1. Reis A, Carrilho M, Breschi L, Loguercio AD. Overview of clinical alternatives to minimize the degradation of the resin-dentin bonds. Oper Dent. 2013;38(4):1-25.

2. Agee KA, Prakki A, Abu-Haimed T, et al. Water distribution in dentin matrices: bound vs. unbound water. Dent Mater. 2015;31(3):205-216.

3. Dash M, Chiellini F, Ottenbrite RM, Chiellini E. Chitosana versatile semi-synthetic polymer in biomedical applications. Prog Polym Sci. 2011;36(8):981-1014.

4. Xu Z, Neoh KG, Lin CC, Kishen A. Biomimetic deposition of calcium phosphate minerals on the surface of partially demineralized dentin modified with phosphorylated chitosan. J Biomed Mater Res B Appl Biomater 2011;98:150-159.

5. Shrestha A, Friedman S, Kishen A. Photodynamically crosslinked and chitosan-incorporated dentin collagen. J Dent Res 2011;90:1346-1351.

6. No HK, Park NY, Lee SH, Meyers SP. Antibacterial activity of chitosans and chitosan oligomers with different molecular weights. Int J Food Microbiol 2002;74:65-72.

7. Kishen A, Shi Z, Shrestha A, Neoh KG. An investigation on the antibacterial and antibiofilm efficacy of cationic nanoparticulates for root canal disinfection. J Endod 2008;34 :1515-1520.

8. Silva PV, Guedes DF, Nakadi FV, Pecora JD, Cruz-Filho AM. Chitosan: a new solution for removal of smear layer after root canal instrumentation. Int Endod J 2013; 46:332338.

9. Calamari SE, Bojanich MA, Barembaum SR, Berdicevski N, Azcurra AI. Antifungal and post-antifungal effects of chlorhexidine, fluconazole, chitosan and its combinations on Candida albicans. Med Oral Patol Oral Cir Bucal 2011;16:e23-28.

10. De Munck J, Vanden PE, Mine A, Van Landuyt KL, Poitevin A, Opdenakr G, et al. Inhibition of enzymatic degradation of adhesive-dentin interfaces. J Dent Res. 2009; 88(12):1101-6.

11. De Moura MR, Aouada FA, Avena-Bustillos RJ, McHugh TH, Krochta JM, Mattoso LHC. Improved barrier and mechanical properties of novel hydroxypropyl methylcellulose edible films with chitosan/ tripolyphosphate nanoparticles. J Food Eng 2009;92: 448-453.

12. Feres M, Figueiredo LC, Faveri VM, Stewart B, William D. The effectiveness of a preprocedural mouthrinse con- taining cetylpyridinium chloride in reducing bacteria in the dental office. J Am Dent Assoc 2010; 141; 415-22.

13. Silvana M, Menezes S, Cordeiro LN, Glauce S, Viana B. Punica granatum (Pomegranate) extract is active against dental plaque. J Herbal Pharmacotherapy 2006; 6(2): 79-92.

14. Kong M, Chen XG, Lui CS, Lui CG, Meng XH, Yu le $\mathrm{J}$. Antibacterial mechanism of chitosan microspheres in a solid dispersing system against E. coli. Colloids Surf B Biointerfaces. 2008; 65(2):197-202.

15. Kong M, Chen XG, Xing K, Park HJ. Antimicrobial properties of chitosan and mode of action: a state of the art review. Int J Food Microbiol. 2010;144(11):51-63.

16. Silva MF, dos Santos NB, Stewart B, De Vizio W, Proskin HM. A clinical investigation of the efficacy of a commercial mouthrinse containing 0.05 percent cetylpyridinium chloride to control established dental plaque and gingivitis. J Clin Dent 2009; 20(2):55-61.

17. Menezes SM, Cordeiro LN, Viana GS. Punica granatum (pomegranate) extract is active against dental plaque. J Herb Pharmacother. 2006;6:79-92

18. Yamagishi Y, Onuma K, Suzuki T, Okada F, Tagami J, et al. (2005) A synthetic enamel for rapid tooth repair. Nature 433: 819 .

19. Van Nieuwenhuysen JP, D'Hoore W, Carvalho J, Qvist V (2005) Longterm evaluation of extensive restorations in permanent teeth. Journal of Dentistry 31: 395-405.

20. Elsaka ES. Antibacterial activity and adhesive properties of a chitosan-containing dental adhesive. Quintessence Int 2012 47(7): 603- 613 .

21. Lobato MF, Turssi CP, Amaral FL, França FM, Basting RT. Chitosan incorporated in a total-etch adhesive system: antimicrobial activity against Streptococcus mutans and Lactobacillus casei. Gen Dent. 2017 ;65(1):62-66.

22. B. Poptani, K. S. Gohil, J. Ganjiwale and M. Shukla. Microtensile Dentin Bond Strength of Fifth with Five Seventh Generation Dentin Bonding Agents after Thermocycling: An in Vitro Study.Contemp Clinic Dent 2012;3:167-171.

23. A. O. Spazzin, B. Carlini Júnior, R. R. Moraes and M. F. Mesquita,. Bonding to Wet and Dry Dentin: Microtensile Bond Strength and Marginal Leakage," Revista de Odontologia da 2008;37: 91-96.

24. T. K. Vaidyanathan and J. Vaidyanathan, "Recent Ad-vances in the Theory and Mechanism of Adhesive Resin Bonding to Dentin: A Critical Review," Journal of Bio-medical Materials Research Part B: Appl Biom 2009;88:558-78. 
25. Amim S, Shetty HK, Varma RV, Amim V, Nair PM. Comparative evaluation of antibacterial activity of total-etch and self-etch adhesive systems: an ex vitro study. J Conserv Dent. 2014; 17(3):266-270.

26. P. Senawongse, C. Harnirattisai, Y. Shimada and J. Tagami. Effective Bond Strength of Current Adhesive Systems on Deciduous and Permanent Dentin. Oper Dent 2004;24: 196-202.

27. Banks P and Thiruve B. Long-Term Clinical Evaluation of Bracket Failure with a Self-Etching Primer: A Randomized Controlled Trial. J Orthodon 2007;34:243-51.

28. Montasser M, Drummond J. R, Roth, Al- Turki C. Rebonding of Orthodontic Brackets. Part II, an XPS and SEM Study. Angle Orthodon 2008;78:537-44.

29. A. Manabe, M. Kanehira, W. J. Finger, H. Hisamitsu and M. Komatsu. Effects of Opacity and Oxygen Inhibition of Coating Resin Composites on Bond Strength to Enamel. Dent Mater 2009:28:552-7. 